\title{
Oxycodone class action lawsuit filed
}

$\mathrm{F}$ red Coulter traces his decision to sue the pharmaceutical company Purdue Pharma (Canada) back to 1994, when a heavy roller in the London, Ontario printing plant where he worked fell and ruptured his spine. To help him cope with the pain, Coulter's physician prescribed him various painkillers. But the only thing that seemed to work was Purdue's opioid analgesic medication, oxycodone (OxyContin). Before long, he began to suspect that he'd become addicted, as he was craving the drug. That led to efforts to obtain oxycodone from several physicians.

"In the end, the doctors refused to see me," recalls Coulter, who is now 57 and retired. What followed was a spiralling disaster in which Coulter began purchasing OxyContin on the street, at a daily cost of up $\$ 100$, which he could not afford. "I was addicted to them badly."

These days, Coulter is off OxyContin, enrolled in a methadone program, and working with lawyers to launch a class action lawsuit in Ontario against Purdue Pharma (Canada), based in Pickering, Ontario.

Filed in the Ontario Superior Court of Justice, the class action suit alleges that Purdue was "negligent in the development, manufacture, distribution, marketing and sale of OxyContin and that the Defendants knew at all material times that anyone who ingest OxyContin would be at significant risk of becoming addicted to it," (www.class action.ca/CMSFiles/PDF/Pharmaceutical /Oxycontin/OXYCONTIN__fresh_as _Amended_Statement_of_Claim.PDF). "The Plaintiffs also allege that the Defendants marketed and promoted OxyContin as less addictive than they knew it to be or ought to have known it to be, and for a wider range of patients and paint treatments than approved by HC [Health Canada]." The plaintiffs are seeking roughly $\$ 350$ million in damages. An Ontario court will determine whether to certify the class action.

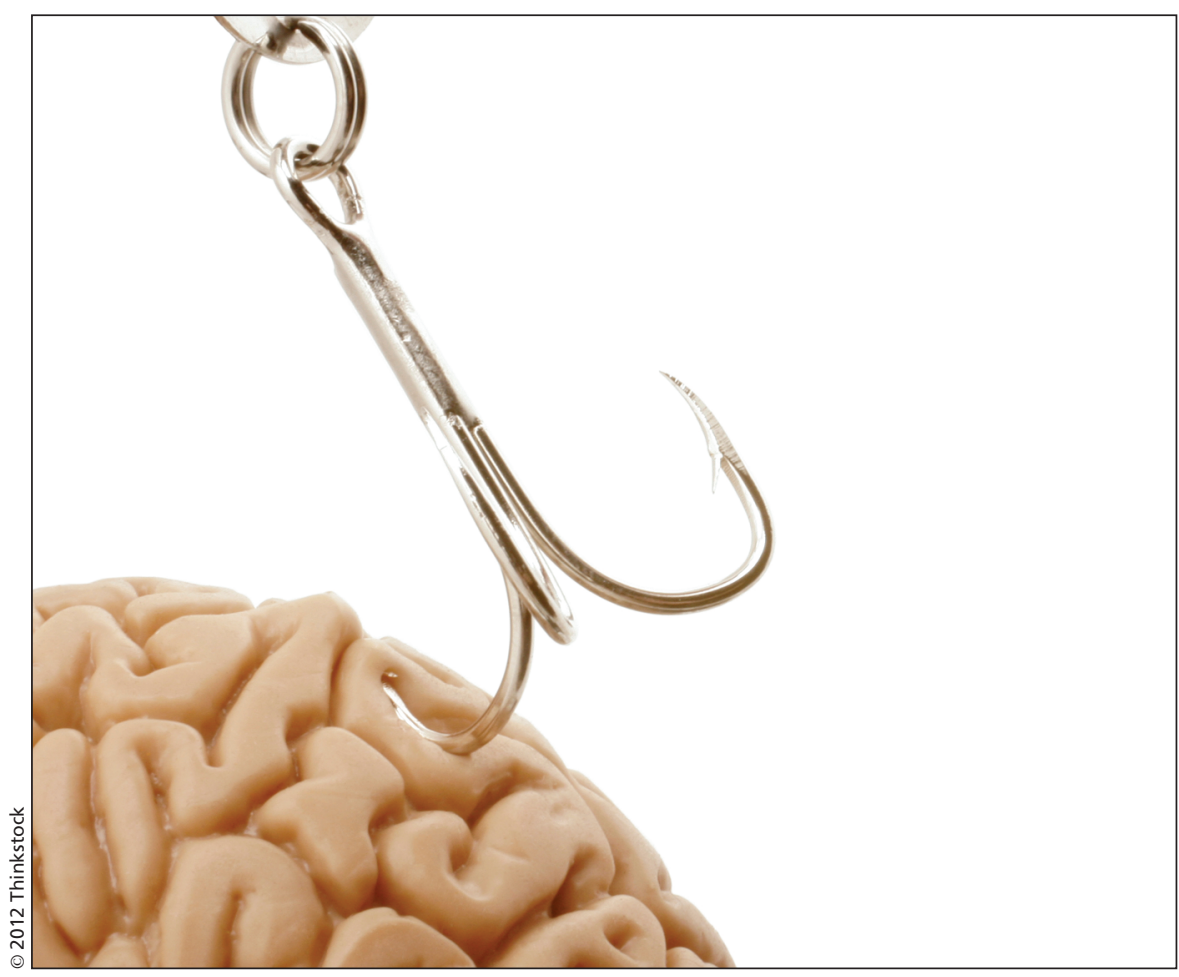

Promotional messages for oxycodone were swallowed "hook, line and sinker," says Dr. David Juurlink, associate professor of medicine, pediatrics, and health policy, management, and evaluation at the University of Toronto and head of the Division of Clinical Pharmacology and Toxicology at Sunnybrook Health Sciences Centre in Toronto.

Coulter believes he did not receive adequate warning about the drug's addictive properties and contends that his physician should have been better informed by Purdue about the risks associated with use of OxyContin, which the firm has since discontinued and replaced with OxyNEO, which is harder to crush and thus, theoretically, tougher to snort or inject. "There are a million other painkillers out there," which could have been prescribed rather than OxyContin, he says.

The bid for class action status in Ontario is the second in Canada. A Nova Scotia court ruled in 2010 that a similar suit failed to meet jurisdictional requirements.

Michael Peerless, a partner and head of the class actions department at Siskinds LLP in London, Ontario who helped prepare the class action, believes the case is bolstered by the
US\$634.5 million settlement reached between Purdue's United States-based operation, Purdue Frederick Company, Inc., and the US Attorney's Office for the Western District of Virginia after it pled guilty in 2007 to fraudulently marketing OxyContin by "falsely claiming that it was less addictive, less subject to abuse and less likely to cause withdrawal symptoms than other pain medications when there was no medical research to support these claims and the US Food and Drug Administration had not approved the claims."

"Even in the face of warnings from health care professionals, the media, and members of its own sales force that OxyContin was being widely abused and causing harm to our citizens, Purdue, under the leadership of its top executives, continued to push a fraudulent marketing campaign that promoted Oxycontin as less addictive, less sub- 
ject to abuse, and less likely to cause withdrawal," US Attorney for the Western District of Virginia John L. Brownlee stated in a press release ( $\mathrm{www}$ .dodig.mil/IGInformation/IGInformation Releases/purdue_frederick_1.pdf).

One of the foundations of Purdue's marketing plan for OxyContin was to create a database profiling the US physicians who were the highest prescribers for opioids, according to a review of oxycodone marketing ( $\mathrm{Am} J$ Public Health 2009;99:221-27).

Purdue Pharma (Canada) Vice President, Corporate Affairs, Randy Steffan writes in an email that it would be "inappropriate" for the firm to comment on legal matters.

"The misuse and abuse of prescription opioids is a societal issue and the solutions require a systematic approach. Industry is only one of many stakeholders and Purdue has been making its effort to contribute to the solution," Steffan adds.

"Purdue supports a comprehensive strategy to deal with narcotics abuse, including restrictions for strong opioids in accordance with the Canadian Guidelines for Opioids Use for Chronic Pain," he writes, adding that "we advocate for careful patient selection and appropriate prescribing and we support clinician education for this purpose."

"Most importantly, we have long advocated easy-to-implement and common sense measures such as opioid limits that restrict prescriptions to no more than 30 days as well as programs to take back and properly destroy unused or expired prescription medication."

Steffan added that the firm also stands behind a real-time database to track opioid prescriptions and use.

But observers suggest Purdue Pharma (Canada) adopted a similar marketing strategy to that of its American cousin, which was alleged in the American settlement to have used a marketing strategy that was premised on the arguments that there is no ceiling dose for opioids; that addiction is rare in pain patients, and that it is safe to use opioids.

"The campaign in Canada was exactly the same as in the US," says Dr. Meldon Kahan, associate professor in the Department of Family Medicine at University of Toronto in Ontario. It was "a massive promotional campaign" that "sought to assuage fears of addiction," he adds.

It would be difficult to separate Purdue's activities in the US and Canada, adds Dr. David Juurlink, associate professor of medicine, pediatrics, and health policy, management, and evaluation at the University of Toronto and head of the Division of Clinical Phar- macology and Toxicology at Sunnybrook Health Sciences Centre in Toronto. "It's called OxyContin in Canada and the US."

Doctors swallowed the firm's promotional messages "hook, line and sinker," Juurlink adds. — Paul Christopher Webster, Toronto, Ont.

CMAJ 2012. DOI:10.1503/cmaj.109-4158

Editor's note: Pursuant to a letter received from Purdue Pharma (Canada), slight modifications have been made to a version of this story that was posted March 21.

That version referred to the original statement of claim filed in the Ontario Superior Court of Justice, in which the plaintiffs alleged a "conspiracy" to market and promote OxyContin as less addictive. At the time the story was written, lawyers did not inform $C M A J$ that an amended statement of claim had been filed, in which the word "conspiracy" was removed.

The previous version also suggested that the courts would likely conduct a class certification hearing this year. But it not known when that hearing will occur. 